$$
\begin{aligned}
& \text { تاثير جهُت شبب بر تنوعزبستى كياهى در قله هزار مسجد، استان خراسان رضوى، ايران }
\end{aligned}
$$

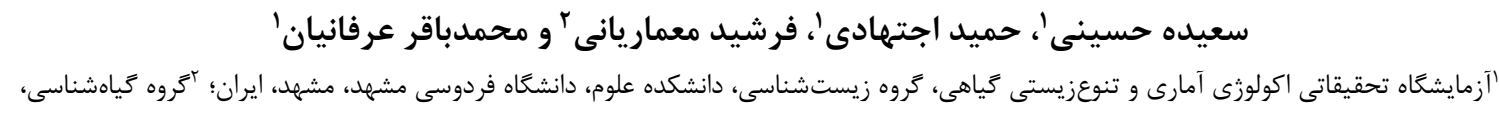

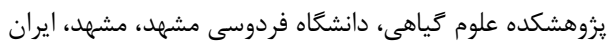

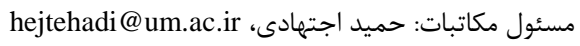

קككيده. رشته كوه هزار مسجد بهعنوان يكى از ارتفاعات مههم شمالشرق ايران است. يوشش كياهى در بخشهاى مرتفع اين منطقه بهخوبى مورد بررسى قرار

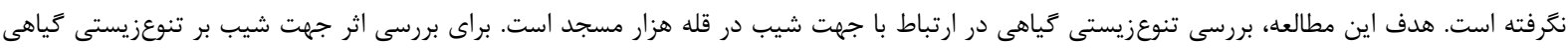

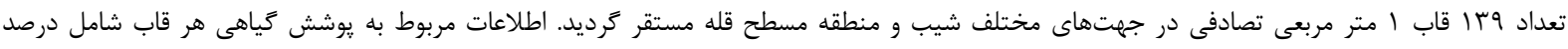

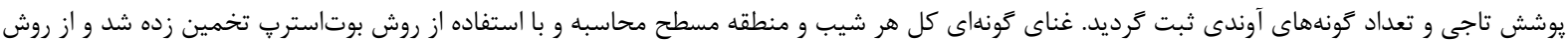

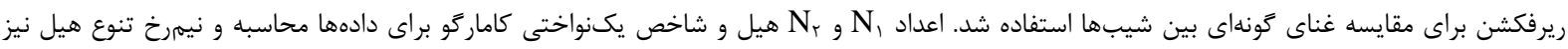

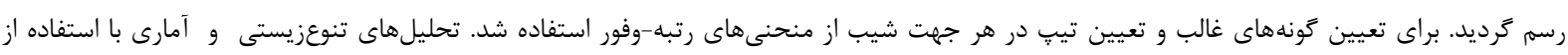

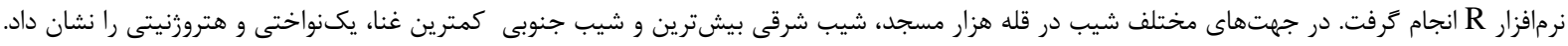

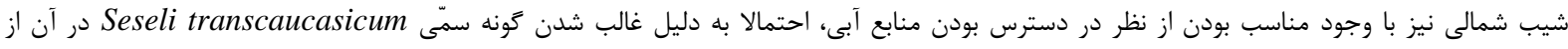

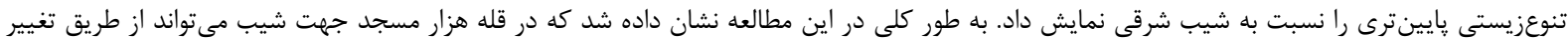
فاكتورهاى محيطى بر تنوعزيستى اثر بخذارد.

وازمهاى كليدى. اكوسيستم كوهستان، اعداد تنوع هيل، جرا، روشهاى پارامترى، غناى كونهاى

\title{
The effects of aspects on the plant diversity of the Hezar-Masjed Summit, Khorassan Razavi Province, Iran
}

\author{
Saeide Hosseini ${ }^{1}$, Hamid Ejtehadi ${ }^{1}$, Farshid Memariani ${ }^{2}$ \& Mohammad Bagher Erfanian $^{1}$ \\ ${ }^{1}$ Quantitative Plant Ecology and Biodiversity Research Lab., Department of Biology, Faculty of Science, Ferdowsi \\ University of Mashhad, Mashhad, Iran; ${ }^{2}$ Department of Botany, Research Center for Plant Sciences, Ferdowsi \\ University of Mashhad, Mashhad, Iran \\ Corresponding author: Hamid Ejtehadi, hejtehadi@um.ac.ir
}

\begin{abstract}
The Hezar-Masjed Mountain range is one of the main highlands of the northeasten Iran. The vegetation of its upper elevations has been poorly studied. This study aimed to compare the plant biodiversity of different aspects of the Hezar-Masjed Summit. A total number of 139 random $1 \mathrm{~m}^{2}$ plots were recorded from different aspects of the study area. In each plot, the abundance and canopy cover percent of vascular plant species were recorded. Hill's numbers (i.e., $\mathrm{N}_{1}$, $\mathrm{N}_{2}$ ) along with the Camargo evenness index and total species richness with bootstrapping approach were calculated. Rarefaction method was used to compare species richness among the aspects. Also, Hill's diversity profile for each aspect was drawn. For each aspect, rank-abundance method was used to evaluate the dominant species. Biodiversity calculations and statistical analyses were performed using $\mathrm{R}$ software. The east- and south- facingslopes were found to have the highest and lowest indices in richness, evenness, and diversity, respectively. Despite adequate water availability in north-facing slopes, they show lower diversity than that of the east-facing slope, probably due to the of dominance of a poisonous species (Seseli transcaucasicum). Our results shown that in the Hezar-Masjed Summit, aspects have different biodiversity which is a result of their various environmental conditions.
\end{abstract}

Keywords. grazing, Hill's indices, mountain ecosystem, parametric methods, species richness 


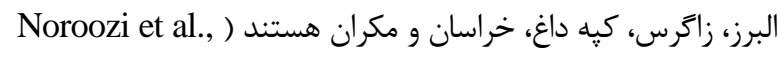
2008). مطالعاتى در زمينه مناطق با ارتفاع زياد در ايران انجام شده است ) Noroozi et al., 2013; Kavousi et al., 2015; أذيا (Noroozi \& Korner, 2018 اندكى در ارتباط با فلور آليى و تنوعزيستى ايران وجود دارد. نقطه

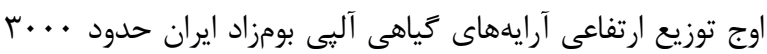

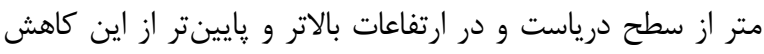

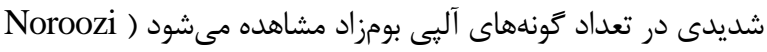

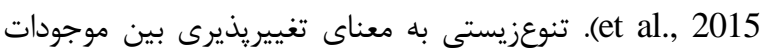

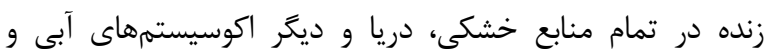

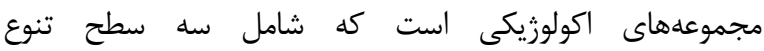
درون گونهاى، بين گونهاى و اكوسيستمها است (Gaston, 2010).

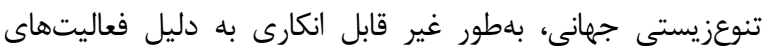

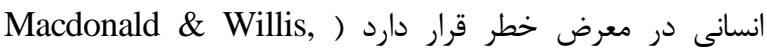

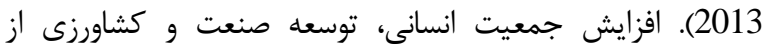

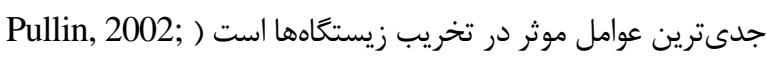

.(Erfanian et al., 2019a, b; Atashgahi et al., 2018 تعداد زيادى شاخص تنوع وجود دارد كه هركدام نقطه

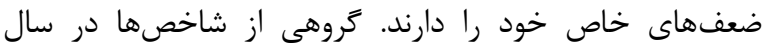

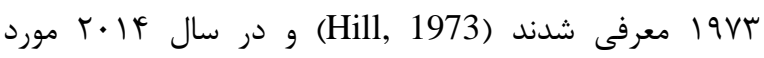
بازنگرى قرار كرفتند (Chao et al., 2014)، به اين دسته از

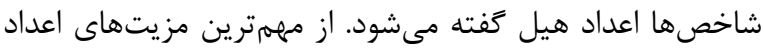

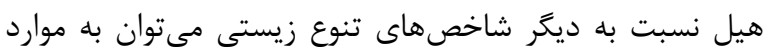
زير اشاره كرد: إ- اعداد هيل واحدهاى بيان كننده تعداد موثر دئر

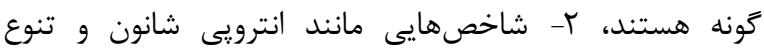

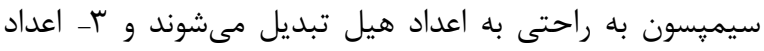

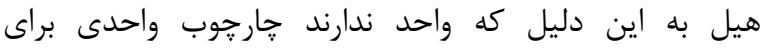

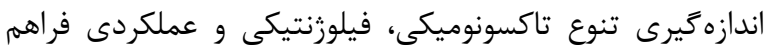

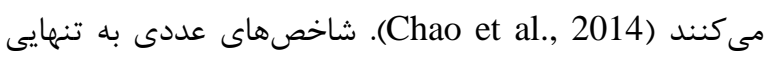
توصيف جامعى از فراوانى و غناى كونهها فراهم نمى كنيند.

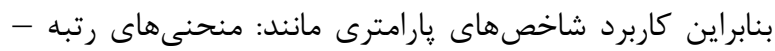

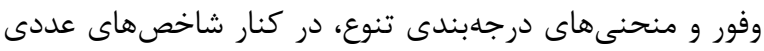

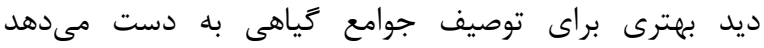

(Motamedi \& Souri, 2016)

رشتهكوه هزار مسجد در بخش شرقى استان فلورى خراسان

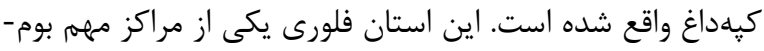

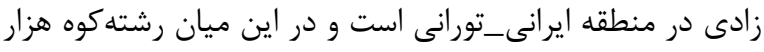

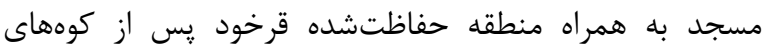

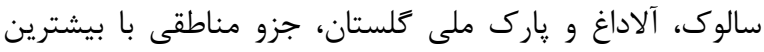

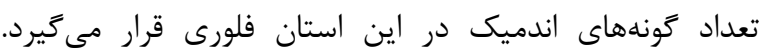

مقلمه كوهستانها حدود هr درصد سطح زمين را تشكيل مىدهند و ميزبان حداقل يك سوم گونههاى گياهى خشكى هستند. بررسى اكوسيستمهاى كوهستانهاى مرتفع يكى از مباحث جذاب براى

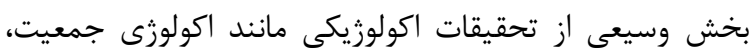

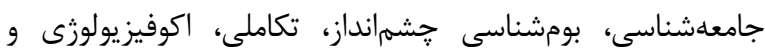
برهمكنشهاى زيستى است. در مصوبهاى كه كنوانسيون

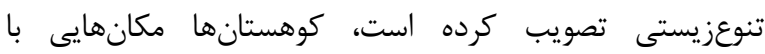
ارزشهاى غيرزيستى، زيستى، اجتماعى، فرهنگى، اقتصادى و

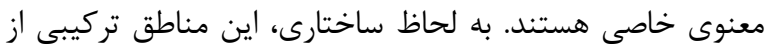

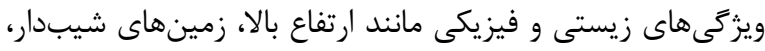

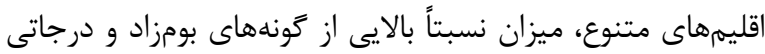
از شكنندگى و دورافتادگى هستند (Martinelli, 2007). در يك نگاه وسيع تنوع و غناى گَونهاى بالاى كوهستانها مى تواند

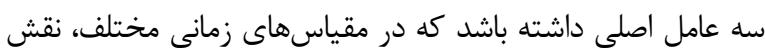

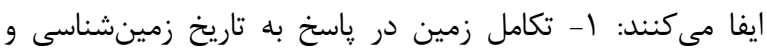
اقليمى، r- سازش گَونهاى به فشارهاى زيستمحيطى و r- تبادلات

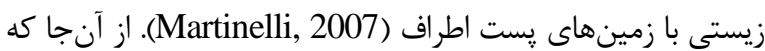
يراكندگى جغرافيايى يوشش گياهى در يكى محيط كوهستانى

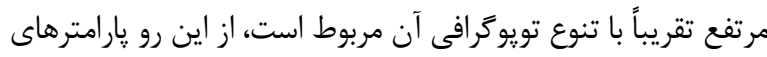

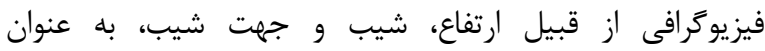

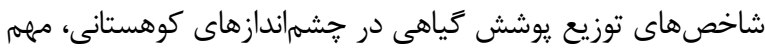
هستند (Hoersch et al., 2002). شواهد نشان مىدهد كه نرخ كرمشدن با افزايش ارتفاع تقويت مىشود و دماى محيطهاى كوهستانى مرتفع نسبت به محيطهاى

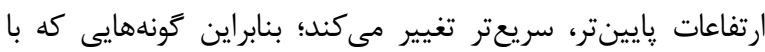
اقليم سرد محيطهاى كوهستانى سازش يافتهاند، حتى اخر تحت تاثير تغيير اقليم دجار انقراض منطقهاى نشوند، با خطر جدى كاهش ليش

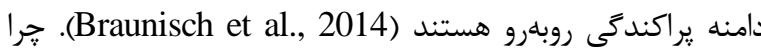
كه اين گونهها در مواجه با تغيير اقليم، از طرفى راهى براى مهاجرت رهات به ارتفاعات بالاتر ندارند و از سوى ديخر با گونههايى كه از ارتفاعات

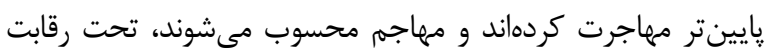
شديد قرار مى گيرند (Thuiller et al., 2014). بنابراين توجه مجنه ويثرنه به تنوعزيستى گونههاى گياهى در ارتفاعات بالا، به خصوص مناطق

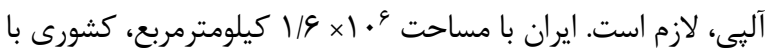

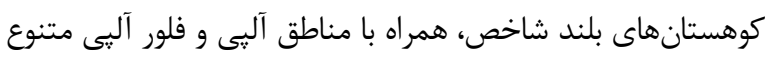

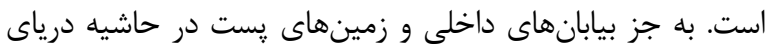

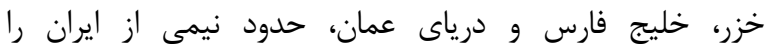
كوهستانهاى بلند تشكيل ميىدهد. مرمترين رشته كوههاى ايران، 


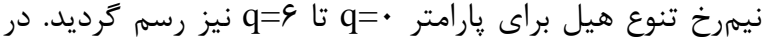

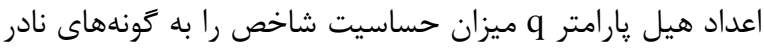

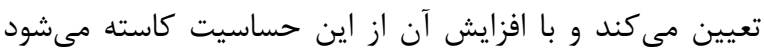
(Erfanian et al., 2019a) يوشش كياهى در هر جهت شيب منحنىهاى رتبه-وفور رسم شد. تمامى تحليلهاى بومشناسى انجام كرفته در اين مطالعه با دراي

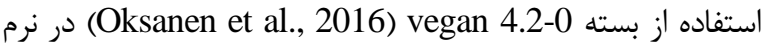
افزار 2017) R 3.3.2 انجام كرفت. براى تحليل آمار استنباطى نتايج تحقيق، ابتدا توزيع نرمال دادهها با آزمون

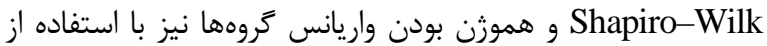

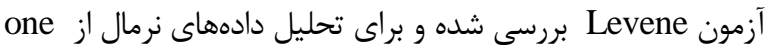

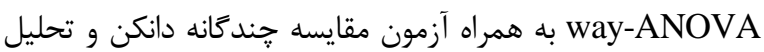
دادههاى غير نرمال از آزمون Kruskal-Wallis به همراه آزمان آزمون

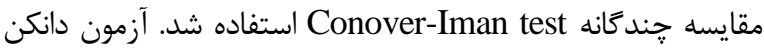
در بسته 1.2-4 agricolae (de Mendiburu, 2016)، آزمون Dinno, ) conover.test 1.1.1 در بسته Conover-Iman test

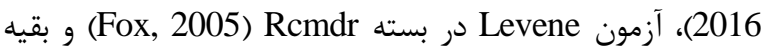

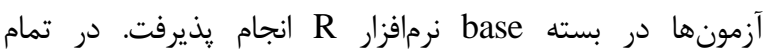
تحليلهاى آمارى سطح معنى دارى ه درصد (ه •|•=

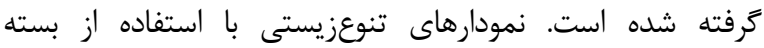
ggplot2 در نرمافزار R رسم شد (Wickham, 2009).

نتايج نتايج غناى كونهاى كل كه در جدول آ آمده است نشان مىدهد

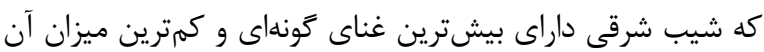
متعلق به شيب جنوبى است. منحنى ريرفكشن كه به منظور مقايسه

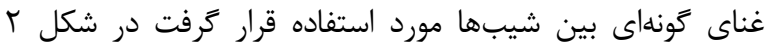

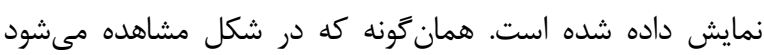
شيب شرقى، شمالى، منطقه مسطح، شيب غربى و جنوبى به ترتيب دئ دادي

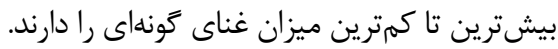

بررسى تنوعزيستى و مقايسه بين شيبها

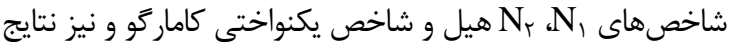

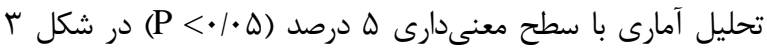

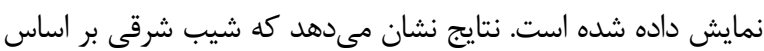

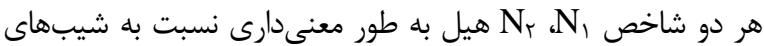

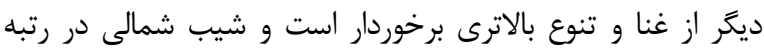

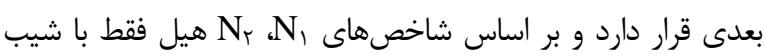
جنوبى تفاوت معنى دار نشان مىدهد و ديكر شيبها با يكديكر تفاوت

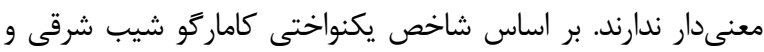

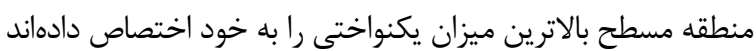

همجنين تنوع بين زيستكاهى (تنوع بتا) زياد در رشته كوه هزار

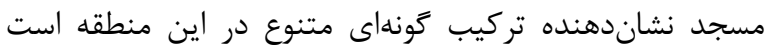
(Memariani et al., 2016) باتوجه به اهميت يوشش كياهى در مناطق كوهستانى و همجنين عدم سابقه مطالعه يوشش كياهى نواحى مرتفع هزار مسجد و نيز

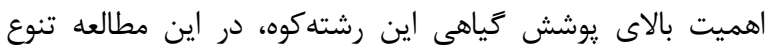
زيستى قله هزار مسجد و نواحى اطراف آن بررسى مى كردائ

مواد و روشها

منطقه مورد مطالعه

قله هزار مسجد دومين قله بلند استان خراسان رضوى است و

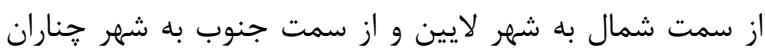

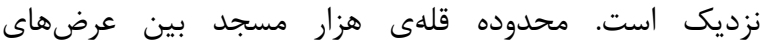
جغرافيايى r) ra/9D, و طولهاى جغرافيايى 

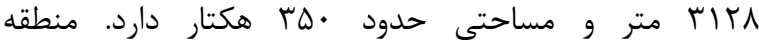
انتخابشده در اين مطالعه، مرتفعترين ناحيه در رشته كوه هزار

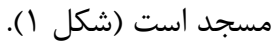

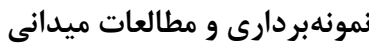

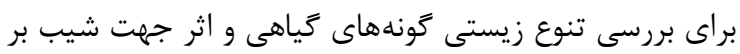

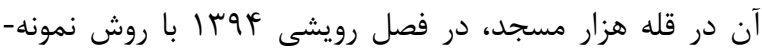
بردارى طبقهبندى شده تصادفى از اين منطقه نمونهبردارى انجام

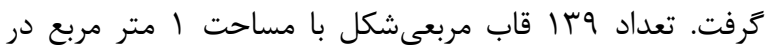
جهات مختلف شيب و منطقه مسطح قله (شيب شمالى و شرقى

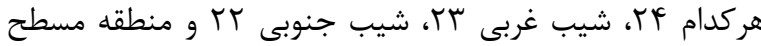

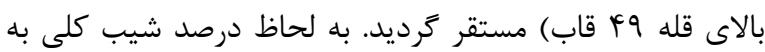
جز منطقه مسطح با درصد شيب صفر، ساير جهات شيب تفاوت קندانى با يكديكر نداشتند. اطلاعات مربوط به يوشش گياهى هر

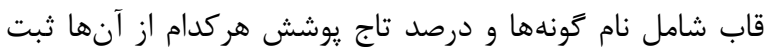

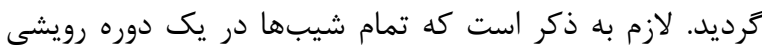
مورد بررسى قرار گرفتهاند بلطوريكه خياهان در شيبهاى مختلف داراى دوره بذر تا بذر يكسان باشند.

تحليل دادهها غناى كونهاى كل هر شيب و منطقه مسطح با استفاده از روش بوتاسترٍ تخمين زده شد و با توجه به يكسان نبودن اندازه

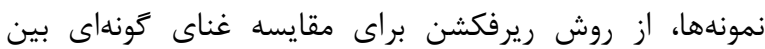
شيبها استفاده شد. شاخصهاى N N (يا نمايى شاخص شانن-

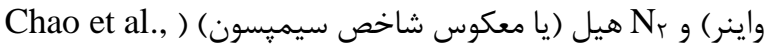

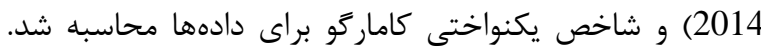




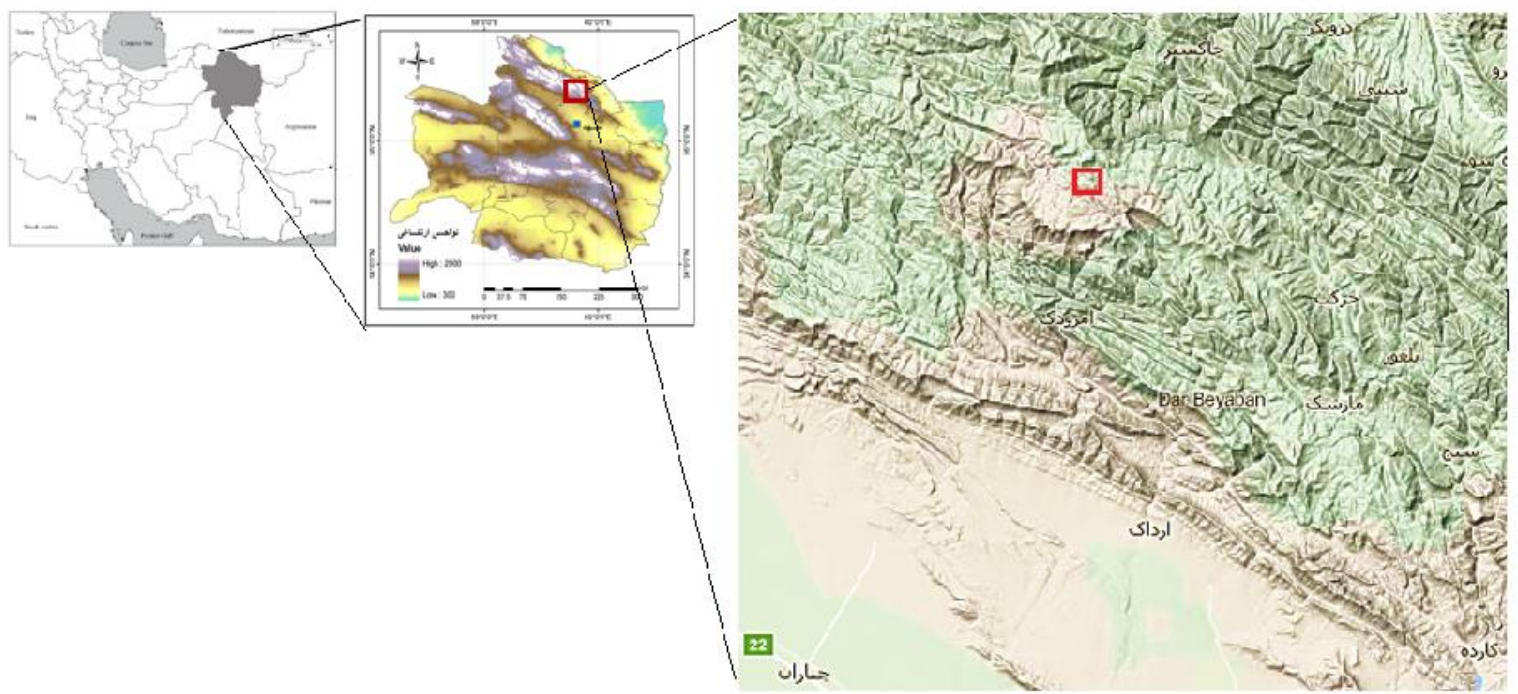

شكل ا- منطقه مطالعه: قله هزار مسجد در استان خراسان رضوى.

Fig. 1. Study area: the Hezar-Masjed Summit in the Khorasan Razavi Province.

جدول ا- مقادير غناى گونهاى محاسبه شده و غناى كونهاى كل مورد انتظار براى هر شيب در قله هزار مسجد.

Table.1. The calculated and expected species richness values for each aspect of the Hezar-Masjed Summit.

\begin{tabular}{r|r|r}
\hline aspect & Species richness & Bootstrapping species richness \\
\hline Flat & 40 & 45.14 \\
North & 42 & 49.27 \\
South & 28 & 31.97 \\
West & 35 & 41.02 \\
East & 50 & 55.95 \\
\hline
\end{tabular}

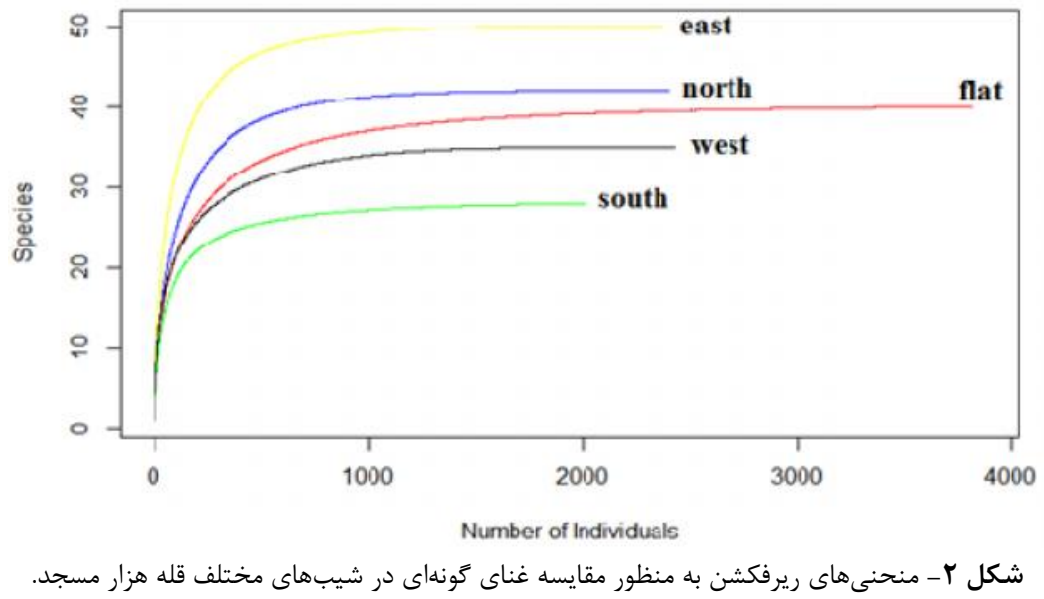

Fig. 2. Rarefaction curves comparing the species richness of aspects in the Hezar-Masjed Summit. 


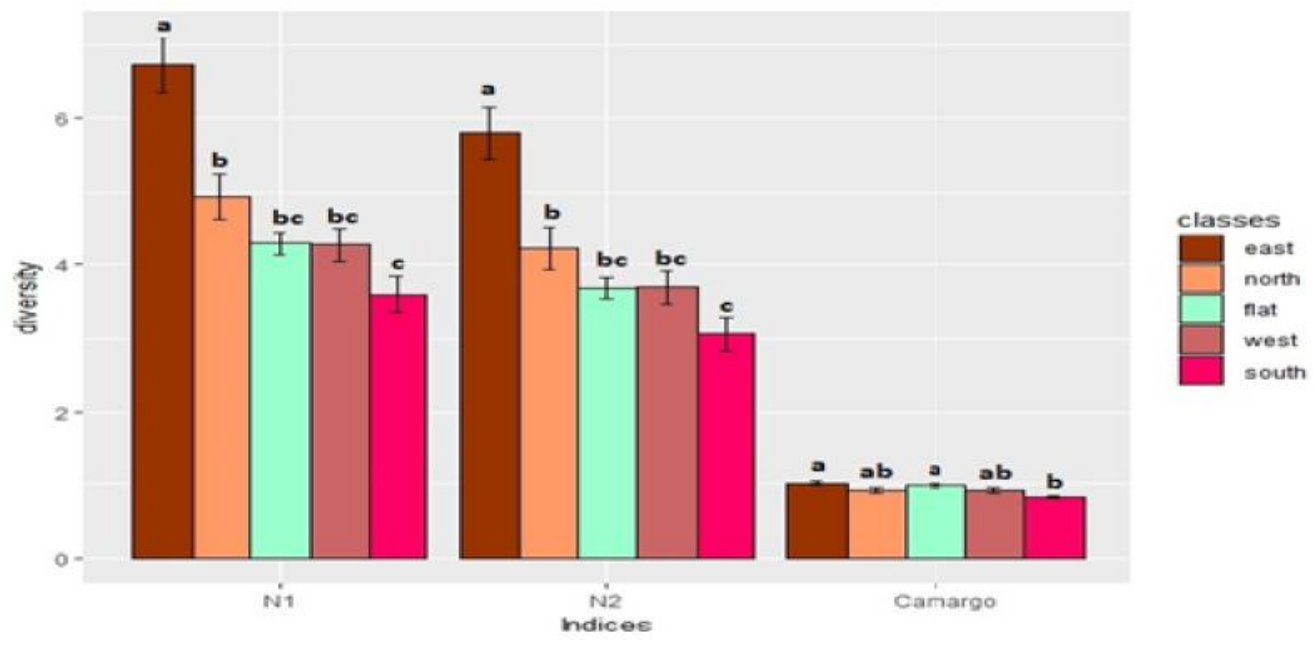

شكل سـ- نتايج تنوع زيستى در قله هزار مسجد به همراه بررسى آمارى شاخصهاى N1 و N هيل و شاخص يكنواختى كاماركو در شيبهاى مختلف. حروف

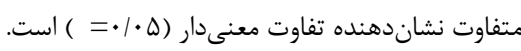

Fig. 3. Biodiversity results in the Hezar Masjed Summit with statistical analysis results for Hill's $N_{1}$ and $N_{2}$ along with the Camargo index in different aspects. Different letters indicate a significant difference $(\alpha=0.05)$.

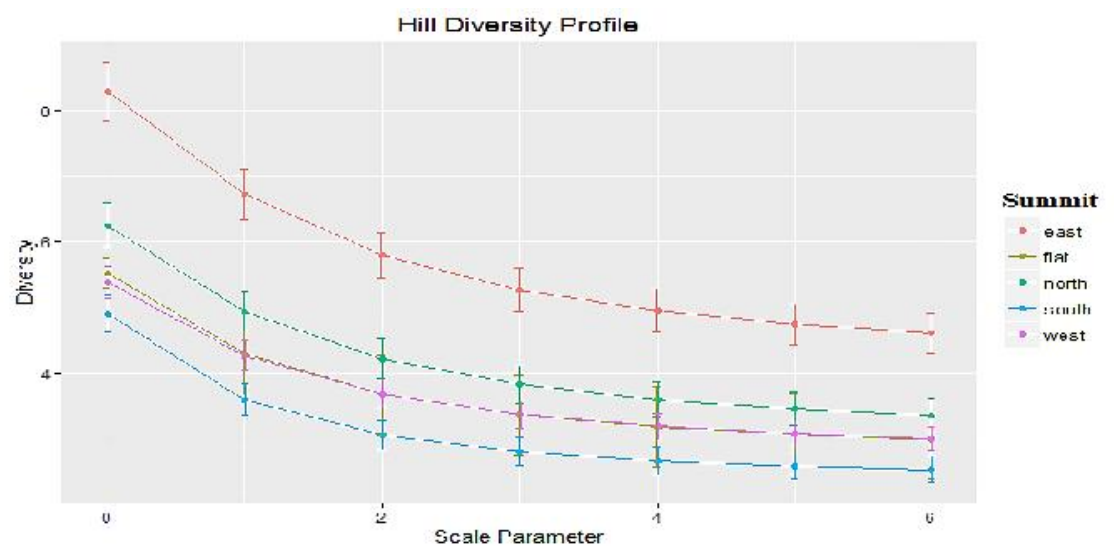

شكل F- نيمر خ تنوع هيل به منظور مقايسه تنوعزيستى كياهى در شيبهاى مختلف در قله هزار مسجد.

Fig. 4. Hill diversity profiles of each aspect in the Hezar-Masjed Summit.

Seseli transcaucasicum ناحيه مسطح گَونه غالب است و گونه

$$
\text { گونه غالب در شيب شمالى است. }
$$

بحث

براى درك صحيح نتايج به دست آمده و جَكَونكى ارتباط بين

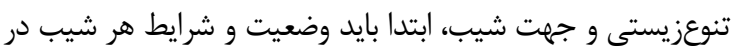
منطقه بررسى شود. شيب جنوبى با بيشترين ميزان دريافت نور و انرزى خورشيدى و نيز اشعه UV كه در ارتفاعات بالا اهميت بيشترى ييدا مىكند (Fioletov et al., 2010)، كمترين ماندكارى رطوبت راد در بين شيبها دارد. با توجه به اينكه شيب جنوبى و غربى نزديكترين شيبها به محل استقرار عشاير در
اما فقط با شيب جنوبى تفاوت معنىدار دارند و ساير شيبها تفاوت معنىدارى را با يكديكر نشان نمى نمهند. نتايج مربوط به به نيمرخ تنوع هيل مربوط به شيبهاى مختلف در شكل ff آمده است.

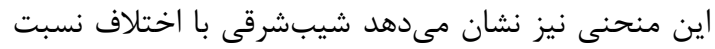

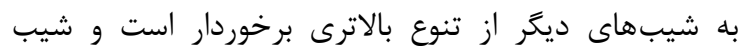
شمالى به ويزه نسبت به شيب جنوبى، در رتبه بعدى قرار مى گيرد. بقيه شيبها با توجه به اين كه منحنى آنها يكديكر را قطع كرده است، قابل مقايسه نيستند.

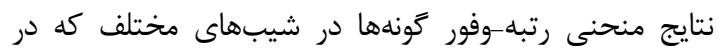

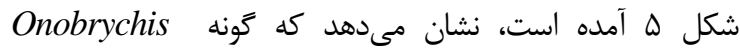
cornuta (L.) Desv. 

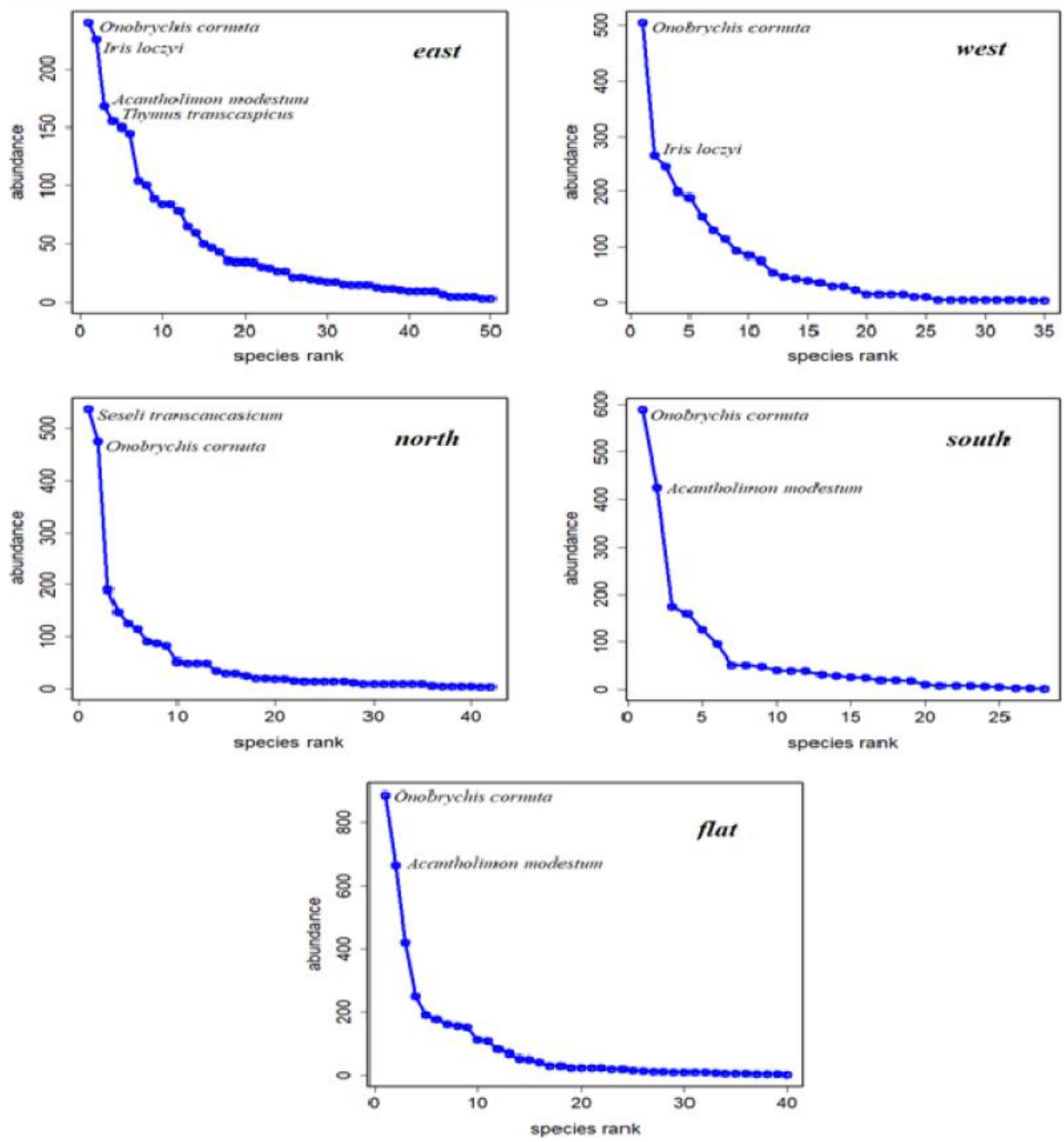

شكل ه- رتبهبندى گونها و تعيين گ خونهاى غالب هر منطقه در قله هزار مسجد.

Fig. 5. Rank-Abundance diagram showing the two dominant species of each aspect in the Hezar-Masjed Summit.

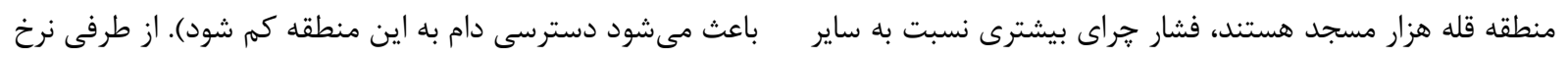

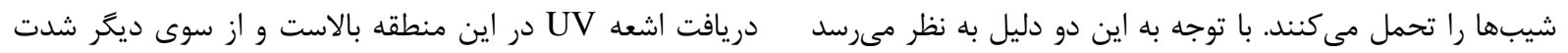

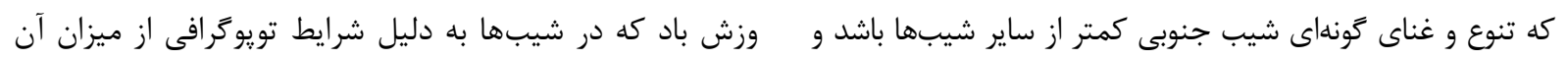

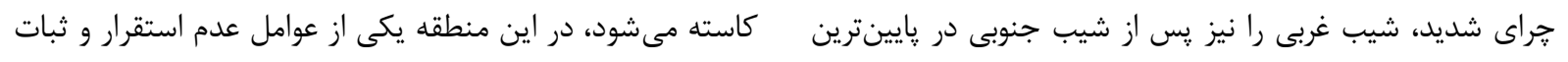

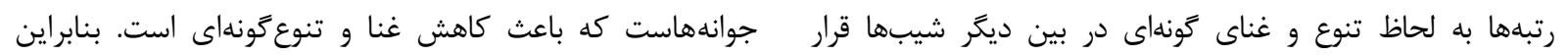

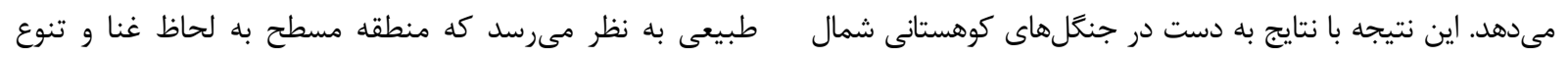

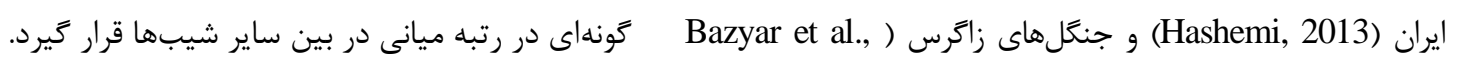

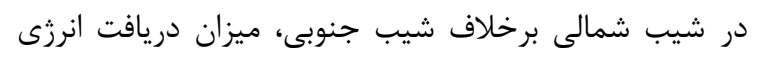
2013) مطابقت دارد اما با نتايج به دست آمده در منطقه حفاظت (

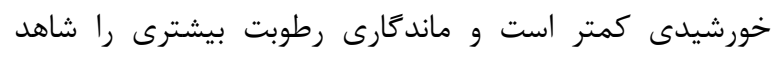
لشكَردر در ملاير (Abbasi Kesbi et al., 2010) متفاوت است.

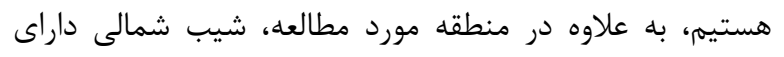

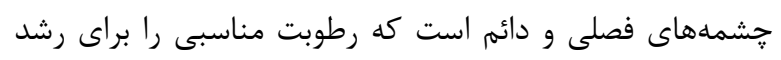

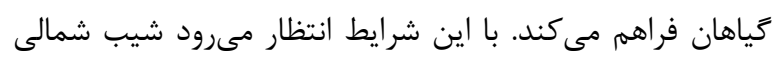

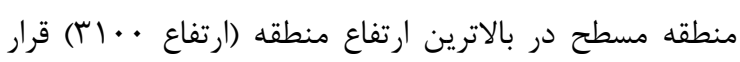

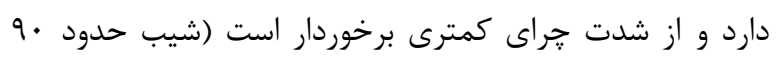

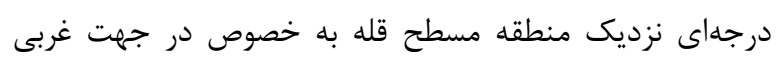


نيز كه در شيبهاى شرقى و غربى دومين گَونه غالب است در فلورا ايرانيكا شيبهاى خشك ارتفاعات بالا معرفى شده است. در نهايت مىتوان كفت در بررسى تنوعزيستى، بين جهات حرئن مختلف شيب در قله هزار مسجد، شيب شرقى از بيشترين غنا، يكنواختى و هتروزنيتى و شيب جنوبى نيز كمترين ميزان آن را دارا است كه اين نتيجه به دليل شرايط مساعدتر شيب شرقى و تخريب ويب

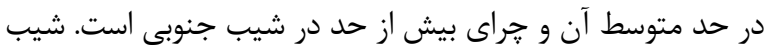
شمالى نيز با وجود شرايط مناسبى كه براى رشد كياهان دارد اما به

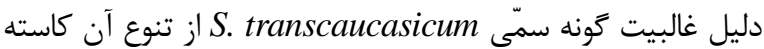
شده است. به طور كلى مىتوان نتيجه گرفت جهت هر شيب بسته به شرايط محيطى فارغ از اينكه در جه ارتفاعى باشد، سابقه تخريبى

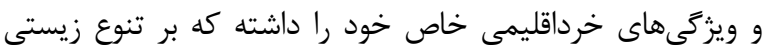

$$
\text { كياهى آن منطقه اثر مى كذارد. }
$$

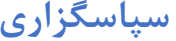

امكانات لازم براى انجام اين :زروهش توسط دانشعاه فردوسى مشهد فراهم گرديده است كه بدين وسيله كمال قدردانى اعلام مى گردد. نويسندكان از آقاى محمد رضا جوهر جىى، دكتر ياسمين ناصح و دكتر حميد موذنى در يزوهشكده علوم گياهى دانشعاه فردوسى مشهد براى شناسايى برخى از زياهان و آقاى على اصغر بصيرى براى كمكهايشان در نمونهبردارى قدردانى مى نمايند.

\section{REFERENCES}

Abbasi Kesbi, M., Tataian, M., Tataian, R. \& Fattahi, B. 2015. Species diversity in relation to physiographic factors in Lashgerdar protected region, Malayer, Iran. Journal of Biodiversity and Environmental Sciences 7: $38-45$.

Atashgahi, Z., Ejtehadi, H., Mesdaghi, M. \& Ghassemzadeh, F. 2018. The existence of a unimodal or monotonic pattern in species richness and diversity along an elevational gradient: a case study in Heydari Wildlife Refuge, NE Iran. Nova Biologica Reperta 5: 291-298.

Bazyar, M., Haidari, M., Shabanian, N. \& Haidari, R.H. 2013. Impact of physiographical factors on the plant species diversity in the Northern Zagros Forest (Case study, Kurdistan province, Marivan region). Annals of Biological Research 4: 317-324.

Bhardwaj, P., Alok, U. \& Khanna, A. 2013. In vitro cytotoxicity of essential oils: A review. Journal of Research in Pharmacy and Chemistry 3: 675-681.

Braunisch, V., Coppes, J., Arlettaz, R., Suchant, R., Zellweger, F. \& Bollmann, K. 2014. Temperate mountain forest biodiversity under climate change: compensating negative by increasing structural complexity. PLoS ONE 9: 1-16.
از تنوع بالاترى نسبت به ساير شيبها برخوردار باشد اما رتبه

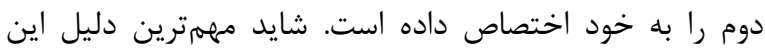
اتفاق را بايد حضور و غالبيت گونه Seseli transcaucasicum دانست كه در جبهه شمالى هزار مسجد از ارتفاع تقريبى ...r متر به بالا مشاهده مىشود. اين گونه داراى خاصيت سميت سلولى است (Bhardwaj et al., 2013) و باعث مسئ مسموميت شديد در دام مىشود. بنابراين تمايل حضور كلههاى دام در اين

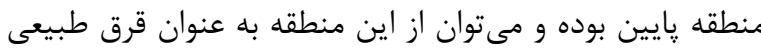

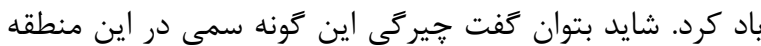

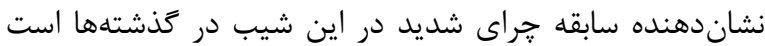

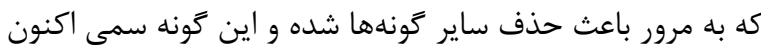

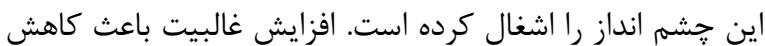

غنا و تنوع در يك منطقه مىشود (Ejtehadi et al., 2009). شيب شرقى در تمام نتايج به دست آمده، از تنوع، غنا و يكنواختى بالايى نسبت به ساير جهات برخوردار است. شايد

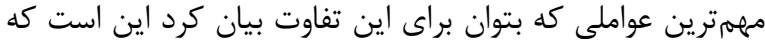
اين جهت شيب از جراى در حد متوسط برخوردار است با اين

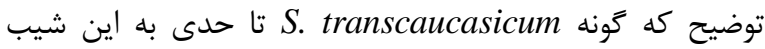
نفوذ كرده و مانع جراى بيش از حد ميىشود و از طرفى در اين شيب غالب نشدهاست. يكى از نشانههاى كاهش غالبيت در اين Acantholimon modestum شيب نزديك شدن دو توني Thymus , Bornm. ex Rech.f. \& Schiman-Czeika transcaspicus Klokov رتبه وفور است (شكل ه). در مطالعه حاضر شيبهاى شمالى و شرقى نسبت به شيبهاى جنوبى و غربى از غنا و تنوع گَونهاى بالايى برخوردارند كه دليل اين امر را مىتوان حضور گونه ارس بuniperus polycarpos K.Koch نايديد شدن اين گونه در ارتفاعات بالا عنوان كرد همان گُونه كه به به دليل تراكم كمتر گونه ارس در دامنههاى جنوبى نسبت به دامنههاى شمالى نور بيشترى به كف رسيده و باعث افزايش غنا و تنوع كونهاى در اين شيب شده است ( Momeni Moghaddam et (al., 2014 ). گونه ارس به دليل سخت شدن شرايط در ارتفاعات

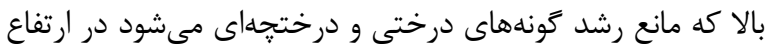

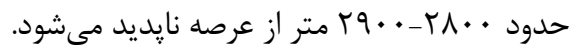
غالبيت گونه O. cornuta را در ارتفاعات بالا ناحيه ايرانى تورانى به اثبات رسيده است (Noroozi et al., 2010)، از طرفى كونه Acantholimon modestum قله غالبيت دارد، گونه انحصارى ايران است و در فلور ايران فقط در

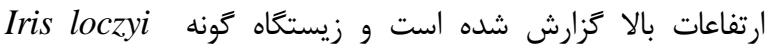


Chao, A., Chiu, C. \& Jost, L. 2014. Unifying species diversity, phylogenetic diversity, functional diversity, and related similarity and differentiation measures through Hill numbers. Annual Review of Ecology, Evolution and Systematics 45: 297-324.

de Mendiburu, F. 2016. Agricolae: statistical procedures for agricultural research. $\mathrm{R}$ package version 1.2-4. https://cran.r-project.org/web/packages/agricolae

Dinno, A. 2016. Conover. Test: conover-iman test of multiple comparisons using rank sums. $\mathrm{R}$ package version 1.1.1. https://cran.r-project.org/web/packages/ conover.test

Ejtehadi, H., Sepehry, A. \& Akkafi, H.R. 2009. Methods of measuring biodiversity. Ferdowsi University of Mashhad Publication, 228 pp.

Erfanian, M.B., Ejtehadi, H., Vaezi, J. \& Moazzeni, H. 2019a. Plant community responses to multiple disturbances in an arid region of northeast Iran. Land Degradation \& Development 30: 1554-1563.

Erfanian, M.B., Ejtehadi, H., Vaezi, J., Moazzeni, H., Memariani, F., Firouz-Jahantigh, M. 2019b. Plant community responses to environmentally friendly piste management in northeast Iran. Ecology and Evolution 9: 8193-8200.

Fioletov, V., Kerr, J.B. \& Fergusson, A. 2010. The UV index: definition, distribution and factors affecting it. Canadian Journal of Public Health 101: I5-I9.

Fox, J. 2005. Rcmdr: A platform-independent basicstatistics GUI (graphical user interface) for R, based on the tcltk package https://cran.rproject.org/web/packages/Rcmdr

Gaston, K.J. 2010. Biodiversity. In Sodhi, N.S. \& Ehrlich, P.R. (eds.). Conservation Biology 27-45.

Hashemi, S.A. 2010. Investigation plant species diversity and physiographical factors in mountain forest in north of Iran. Journal of Forest Science 26: 1-7.

Hill, M.O. 1973. Diversity and evenness: A unifying notation and its consequences. Ecology 54: 427-432.

Hoersch, B., Braun, G. \& Schmidt, U. 2002. Relation between landform and vegetation in alpine regions of Wallis, Switzerland. A multiscale remote sensing and GIS approach. Computers, Environment and Urban Systems 26: 113-139.

Kavousi, K., Nejad Sattari, T., Asri, Y., Ejtehadi, H. \& Khavarinejhad, R.A. 2015. Floristic changes at Khersan glacier territory, Alamkuh Mountain, Central Alborz, north of Iran. Biodiversitas 17: 11-15.

Macdonald, D.W. \& Willis, K.J. 2013. Key topics in conservation biology 2. Wiley-Blackwell, $528 \mathrm{pp}$.

Martinelli, G. 2007. Mountain biodiversity in Brazil. Brazilian Journal of Botany 30: 587-597.
Memariani, F., Akhani, H. \& Joharchi, M.R. 2016. Endemic plants of Khorassan-Kopet Dagh floristic province in Irano-Turanian region: diversity, distribution patterns and conservation status. Phytotaxa 249: 31-117.

Momeni Moghaddam, T., Akbarinia, M., SaghebTalebi Kh., Akhavan, R. \& Hosseini, S.M. 2014. Impact of physiographic factor on biodiversity indices of herbaceous species juniper stands in Hezar Masjed Mountains. Journal of Plant Research 27: 511-519.

Motamedi, J. \& Souri, M. 2016. Efficiency of numerical and parametrical indices to determine biodiversity in mountain rangelands. Acta Ecologica Sinica 36: 108-112.

Noroozi, J., Akhani, H. \& Breckle, S.W. 2008. Biodiversity and phytogeography of the alpine flora of Iran. Biodiversity and Conservation 17: 493-521.

Noroozi, J., Akhani, H. \& Willner, W. 2010. Phytosociological and ecological study of the high alpine vegetation of Tuchal Mountains (Central Alborz, Iran). Phytocoenologia 40: 293-321.

Noroozi, J. \& Körner, Ch. 2018. A bioclimatic characterization of high elevation habitats in the Alborz Mountains of Iran. Alpine Botany 128: 1-11.

Noroozi, J., Moser, D. \& Essl, F. 2015. Diversity, distribution, ecology and description rates of alpine endemic plant species from Iranian mountains. Alpine Botany 126: 1-9.

Noroozi, J., Willner, W., Pauli, H., \& Grabherr, G. 2013. Phytosociology and ecology of the high alpine to subnival scree vegetations of $\mathrm{N}$ and NW Iran (Alborz and Azerbaijan Mts.). Applied Vegetation Science 17: 142-161.

Oksanen, J., Blanchet, G.F., Friendly, M., Kindt, R., Legendre, P., McGlinn, D., Minchin, P. R., O'Hara, R.B., Simpson, G. L., Solymos, P., Stevens, M. H. H., Szoecs, E. \& Wagner, H. 2016. Vegan: Community ecology package. R package version 2.4-0. https://cran.rproject.org/web/packages/ vegan

Pullin, A. S. 2002. Conservation biology. Cambridge University Press, $355 \mathrm{pp}$.

R Core Team. 2017. R: A language and environment for statistical computing. $\mathrm{R}$ foundation for statistical computing, Vienna, Austria. https://www.rproject.org

Thuiller, W., Guéguen, M., Georges, D., Bonet, R., Chalmandrier, L., Garraud, L. \& Lavergne, S. 2014. Are different facets of plant diversity well protected against climate and land cover changes: A test study in the French Alps. Ecography 37: 12541266.

Wickham, H. 2009. ggplot2: Elegant graphics for data analysis. Springer-Verlag, New York.

How to cite this article:

Hosseini, S., Ejtehadi, H., Memariani, F. \& Erfanian, M.B. 2020. Effects of slope aspect on plant diversity in Hezar Masjed summit, Khorassan Razavi province, Iran. Nova Biologica Reperta 7: 355-362. (In Persian).

حسينى، س.، اجتهادى، ح.، معماريانى، ف. و عرفانيان، م.ب. و9 وبا. تاثير جهت شيب بر تنوع زيستى كياهى در قله هزار مسجد، استان خراسان رضوى،

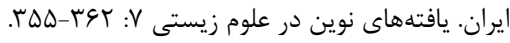

